\title{
INTRODUCTION \\ Hierarchy, Value, and the Value of Hierarchy
}

\author{
Naomi Haynes and Jason Hickel
}

\begin{abstract}
Many of the communities in which anthropologists work are hierarchically organized, and the people who live in them often describe this arrangement in positive terms. Nevertheless, anthropologists rarely paint hierarchy in a favorable light. This special issue aims to question this tendency with ethnographic insights into social contexts where hierarchy is regarded as a desirable social good. By way of an introduction to the research articles, we explore those aspects of Western thought that make it difficult for anthropologists to take hierarchy seriously. In addition, we develop an interpretive approach that treats hierarchy both as a relational form and as a theoretical model-that is, as a framework for understanding value-drawing in part on our own ethnographic research in southern Africa.
\end{abstract}

Keywords: hierarchy, individualism, liberalism, Louis Dumont, social organization, southern Africa, value

Modern man is virtually incapable of fully recognizing [hierarchy]. For a start, he simply fails to notice it. If it does force itself on his attention he tends to eliminate it as an epiphenomenon. Should he finally accept it, as I did, he must still take pains to see it as it really is, without attributing imaginary properties to it. By contrast, all the difficulties vanish if we keep it firmly before our eyes, accustom ourselves to following its outlines and implications, and rediscover the universe in which it operates. (Dumont ([1970] 1980: xlvii)

Hierarchy is not the sort of thing one typically hears Western academics describe in positive terms. There are both political and intellectual reasons why this is so. With regard to the former, it is not difficult to see that the notion of hierarchy runs straight against the grain of the liberal sensibilities that most scholars share, and placing hierarchy in a favorable light therefore seems to fly in the face of these core political commitments. In terms of the latter, in the current intellectual 
climate, perhaps particularly in anthropology, we are still struggling to get past the preoccupation with power that has been central to disciplinary thought over the past two decades. As Marshall Sahlins (2004: 138-154) has pointed out, this orientation has produced a reductive overemphasis on the subject, which in turn has made it difficult to take cultural systems, including those characterized by hierarchy, seriously (also see Rio and Smedal 2009b: 2-3). As Sahlins (2004: 149) puts it, under these intellectual circumstances such systems "appear as the political cum intellectual enemy," monuments to structures of power that, when compared to "the experience-near, embodied world of excluded subjects, demanding their own identities and contesting the authoritative narratives of the larger society," seem like inflexible anachronisms.

Despite these barriers to treating hierarchy as a serious object of study, much less as a positive social phenomenon, we believe that as anthropologists we cannot ignore this topic. This is true first and foremost because many of the communities in which we work are organized hierarchically, and people in these communities often represent hierarchy in positive terms (see, e.g., Ansell 2010; Ferguson 2013; Haynes 2012; Hickel 2015; Iteanu 2013; King 2014; Scherz 2014; Smith 2007). While individualism and egalitarianism are central to Western conceptions of justice and the good, many people in hierarchical societies see them as immoral and destructive, as eroding the relationships that make meaningful personhood possible. Our primary aims in this special issue are therefore to explore a variety of ethnographic contexts in which hierarchy is portrayed as desirable and to examine the role of hierarchy in people's efforts to produce a social world that reflects their understanding of a good society (Robbins 2013a). Situating hierarchy in local conceptions of the good life in turn opens the way for us to speak not only of hierarchical social organization but also of values. This connection is most immediately evident in the fact that when people speak positively of hierarchy, they are speaking about what they value. Even more fundamentally, hierarchy draws our attention to the way that values are organized with respect to each other, since values are hierarchically ranked, with some being more important than others. Hierarchy is therefore a central component of any theory of value (Dumont [1970] 1980: 20).

In light of these observations, our goal in this special issue is twofold. First, as an ethnographic project, this issue foregrounds hierarchy as a mode of social organization, building on a solid foundation of important work (Mosko and Jolly 1994; Peacock 2015; Rio and Smedal 2009a) in an effort to expand our understanding of the sorts of relational worlds that, for reasons we describe in more detail below, anthropologists have found difficult to engage in empathetic terms. Second, we seek to explore the central position of hierarchy in the process and production of value. Here again we build on previous discussions in the discipline, where the topic of value is enjoying something of a revival (see, e.g., Eriksen 2012; Graeber 2001; Otto and Willerslev 2013; Pedersen 2008; Robbins $1994,2004,2015)$. In what follows, then, we address hierarchy both as a mode of social organization and as a model for social theory, while also seeking out connections between these two approaches. Our goal is to cultivate a conversation around the issue of hierarchy animated by difficult questions. Why, 
for instance, should anthropologists-and especially young scholars interested in the neo-liberal moment-be concerned with hierarchy? What is the place of hierarchy in contemporary social theory? How are we to think about reassertions of hierarchy in the era of globalization? How have people leveraged ideas about hierarchy in order to challenge liberal models of the social good? More specifically, how have societies reimagined and reconfigured the ideas and institutions of Christianity, democracy, and development-which have figured so often in social theory as forces for egalitarianism and individualism-to suit their own hierarchical values and goals? And how has hierarchy itself been retooled, reinvigorated, and restructured, especially in contexts of social change and conjuncture?

In this introduction, we offer a theoretical framework for these questions, which are variously engaged by the authors featured in this special issue. We begin by specifying what we mean by hierarchy and then go on to consider why this topic is especially difficult for contemporary Western scholars, in particular, to think with. We follow this discussion with some short ethnographic examples from our own work in southern Africa that illustrate the importance of hierarchy in the specific contexts of Christian practice and political democratization. These examples then open the way for a brief treatment of the topic of value. We conclude by providing an overview of the various contributions to this issue.

\section{Dealing with Dumont}

As we turn our attention to developing a definition of hierarchy, we begin by positioning ourselves in relationship to the theorist whose work has unquestionably had the greatest impact on anthropological engagement with this topic. We have already invoked Louis Dumont in the epigraph above, and his influence is evident throughout this issue. ${ }^{1}$ Beyond the fact that most of the contributions engage with Dumont directly, this introduction is also indebted to his work. That said, we want to make clear from the outset an important distinction between our analysis and that offered by Dumont. While we recognize the merit of Dumont's holism, not least as an analytic device that brings many of the unquestioned assumptions of Western individualism to the fore, in the discussion that follows we hope to avoid the confusion that the tight coupling of holism and hierarchy in Dumont's anthropology sometimes creates by drawing a distinction between what we mean by hierarchy as a model of value and hierarchy as a social form.

In Dumont's work, hierarchy and holism are inextricably linked. This is because hierarchy for Dumont is defined by what he terms 'encompassment' and more specifically encompassment "of the contrary" (Dumont 1986: 252; see also Dumont [1970] 1980: 240). By this he is referring to the relationship between a whole and its parts; the latter are at once constitutive of and, as such, identical to the whole, and yet they are different from and, as such, contrary to it. ${ }^{2}$ Hierarchy therefore presupposes a whole. In a detailed discussion of Dumont's holism, Bruce Kapferer (2010) notes that for Dumont the whole is not social or territorial. 
It does not, in other words, connote the boundaries of a society or community but is instead ideological: it is a system of ranked and competing values. Kapferer thus views Dumont's holism as a methodology aimed at the comparative study of ideology across a large swath of human existence-a method "that assumes that values in relations are never balanced or equivalent ... but hierarchical when conceived through and defined in relation to the whole" (ibid.: 198-199).

Given Kapferer's clarifications, so far we find little to disagree with in Dumont. The notion of hierarchy more generally is fundamental to any theory of value, and toward the development of such a theory hierarchical encompassment is a compelling idea. Nevertheless, we are cautious about taking up Dumont's work for several reasons. First, at least some readers will feel that Dumont has found in non-Western societies not only a point of contrast to the modern West, but also, and more problematically, a perennial past in the present (Appadurai 1988; Fabian 1983). Faced with such critiques, one employs Dumont's theory only at the risk of being thought guilty by association of a neo-colonialist conceit. So too, while we find it helpful to explore values in terms of hierarchical encompassment, we want to keep our distance from a reading of Dumont that cites his occasional references to a 'paramount value' (Dumont 1986) as evidence that all values can ultimately be reduced to one. ${ }^{3}$ Finally, and most importantly for the purposes of this issue, we must make clear that the definition of hierarchy that Dumont puts forward for values-hierarchy as encompassment-is not the same as the definition of hierarchy that we will be using when we speak of it as a social form. This requires a bit of explanation.

For Dumont, social hierarchy comes from a kind of holism that is very different from the ideological holism we have just described. In this second usage, the whole is not "an analyst's construction" but rather "a conception in the indigenous culture" (Robbins 1994: 31). Here, the integrity of the whole is the central concern behind much, if not all, of social life, and the latter is therefore organized in such a way as to reproduce and reorient the whole on terms that are ideologically salient, such as the religious notion of purity. Drawing on this socio-cultural definition of holism, it is no surprise that for Dumont social hierarchy is also marked by encompassment: in the case of India, lower castes are encompassed by higher castes so as to preserve the purity of the whole. It is in this interpretation of holism and hierarchy as social forms that we diverge from Dumont. Laying aside the vexed question of whether holism is indeed an indigenous conception in South Asia (we leave that to the regional specialists), we nevertheless want to make clear that while there may be cultural settings in which social hierarchy does take the form of encompassment, it is by no means necessary to define social hierarchy in these terms. ${ }^{4}$ Indeed, in this introduction we have chosen not to do so. Rather, our definition of hierarchy as a social form refers not to encompassment but rather to difference and asymmetry, and often also to rank. Examples from the ethnographic record of social hierarchy as we define it include the rich literature on 'clientistic' relationships (e.g., Eisenstadt and Roniger 1980), seniority (e.g., Pritchett 2001; Richards 1982), and what James Ferguson (2013) has recently called ties of 'dependence' (see also Barnes 1967; Bolt 2014; Scherz 2014)..$^{5}$ In addition, we would note that based on this 
definition it is possible for hierarchy to co-exist with a certain kind of ontological egalitarianism. While in some cases hierarchical sociality presupposes basic ontological difference-that is, the people who inhabit different ranks in the system are considered to be fundamentally different types of beings, as in the caste system as Dumont describes it-in other cases people are regarded as ontologically equivalent, and the various ranks of the system are theoretically and often actually open to anyone. In such instances, 'egalitarian hierarchy' is not a contradiction in terms, but rather an important analytical descriptor.

In keeping with our reading of Dumont as we have outlined it here, it should be clear that what is most interesting to us about hierarchical social arrangements is the way that they reveal particular ideological arrangements, that is, topographies of value. Put differently, we might say that we are not simply interested in hierarchy as such, but rather in why hierarchy has emerged as so important in so many ethnographic contexts. Addressing this issue means engaging with value and, more specifically, with the values that hierarchical relationships express. In this way, while there are certainly parts of Dumont's complicated apparatus that we leave behind or do not take up, our discussion in this introduction is offered very much in the spirit of Dumont, both in the connections we draw between social forms and values and in our insistence on the structuring influence and hierarchical arrangement of the latter. It is in a similar spirit that we now turn our attention to a more detailed discussion of the problems that attention to hierarchy-and particularly attention to hierarchy as a moral good-raises in contemporary anthropology.

\section{The Problem of Hierarchy}

We are by no means the first anthropologists to observe that hierarchy represents an uncomfortable topic for the discipline. As Dumont's words have already reminded us, hierarchy has for decades presented a problem to modern, Western anthropologists. One of the reasons for this is that anthropology-and particularly American cultural anthropology-is very firmly rooted in the classic liberal tradition that underpins Western academia. Kant's enlightenment mantra ("Dare to be wise!") called for individuals to exercise their own capacity for critical thought without relying on the guidance of establishment authority figures and to question the conventional wisdom that such figures hand down. "For true enlightenment," Kant said, "all that is needed is freedom." Anthropology has taken up this enlightenment project and added its own spin, drawing on the perspectives of other cultures to gain distance from the entrenched assumptions and taken-for-granted values of our own. Indeed, many of the Boasians believed that this cross-cultural relativist stance provided the anthropologist with a sort of transcendence from the cognitive limitations of any single culture and therefore a special degree of freedom.

Yet it is not only their own freedom that anthropologists have been concerned to achieve, but also that of others. We can see this even in the early stages of the discipline's history. The Boasian tradition began in large part as an anti-racist 
project-an ambitious attempt to upend the dominant social hierarchies that characterized early-twentieth-century America. More recently, anthropologists have been at the forefront of challenging gender hierarchies and other social inequalities, both at home and abroad. It is for these reasons that anthropology departments across the world have developed a reputation for being bastions of progressive thought and action. At the heart of this movement is a concern, once again, for human freedom, conceived as the emancipation of the suffering subject (cf. Robbins 2013a) from the constraints of oppressive social norms, of which hierarchies of race and gender seem to be the most troubling. On a more abstract theoretical level, we can see this concern for freedom reflected in the long-standing debates that anthropologists have engaged in over the tension between structure and agency (cf. Obeyesekere 1992; Sahlins 1995), with the contemporary consensus leaning heavily toward the latter-a stance that is as much political as analytical. As we pointed out above, the analytical project of recognizing and describing the agency of the subject against the material and symbolic structures that 'constrain' or overdetermine agency runs parallel to the political project of emancipating the subject by challenging hierarchies.

In other words, a deep tension exists in liberal thought between the value of individual freedom, on the one hand, and the social hierarchies that are thought to constrain freedom, on the other. In light of this tension, we need to ask ourselves, why are freedom and hierarchy regarded as incompatible? We argue that it has to do with the particularly Western conception of freedom that this formulation assumes. Webb Keane's work offers insights into how this plays out. Demonstrating that the dominant Western conception of freedom-that which underpins narratives of modernity and progress-focuses on human emancipation as a project of progressive self-mastery, Keane (2007: 6) states: "If in the past humans were in thrall to illegitimate rulers, rigid traditions, and unreal fetishes, as they become modern they realize the true character of human agency. Conversely, those who seem to persist in displacing their own agency onto such rulers, traditions, or fetishes are out of step with the times, anachronistic premoderns or antimoderns." Liberation, in other words, is conceived as the emancipation of the individual from the arbitrary authority of others.

This conception of freedom presupposes a fundamental dichotomy between the individual and society. The individual is regarded as the proper locus of reason and the source of 'authentic' desire. The individual exists prior to society, which is imagined as a series of external constraints. Social norms, rules, values, and beliefs are thought to overdetermine the desires of individuals and appear as a form of bondage. The process of liberation, then, involves excavating and asserting the inner autonomous agency of the individual. It is, above all, a process of self-realization. These assumptions about the tension between the individual and society appear repeatedly in Western social science (Sahlins 2008) and, in various iterations, inform the work of Hegel, Freud, and much of the structural functionalist tradition. Indeed, they even seem to inform Marx's theory of ideology: the 'false consciousness' handed down by society-which reflects the interests of a ruling class-precludes objective knowledge of the external world and therefore stifles the expression of true political agency and desire. 
In view of all this, it becomes clear why hierarchy poses a problem for the liberal conception of freedom: it represents an arrangement wherein persons are embedded in relations of interdependence that appear to hamper their prospects for self-mastery. The subject entangled in hierarchies appears as the antithesis of the modern political subject-the disembedded, free-thinking, rights-bearing individual.

We know, of course, that these assumptions are incorrect. The subject does not precede society or social norms but is in fact formed through those norms. Michel Foucault and Judith Butler are often credited with pointing this out, but it is an observation that is nearly as old as anthropology itself. Persons do not exist outside of social relationships-or, as the Boasians would have it, persons do not exist outside of culture. If this is the case, then the idea of agency-and of freedom-needs to be rethought. The subject's capacity for agency does not inhere in some authentic inner self or a prior substratum of personhood. Rather, it is a product of the processes-the norms and the relationships, including hierarchical ones-that produce the subject in the first place. As Charles Taylor (1989: 33) has argued, human agency is what is possible within some given moral orientation rather than an absolute freedom from all orientations. Based on this viewpoint, we need to relativize our conception of agency to take into account choices that people make and desires that they hold which may not accord with our assumptions about what counts as liberation or resistance (see, e.g., Frank 2006, Meyer and Jepperson 2000; Peacock 2013).

As some of the contributions to this special issue demonstrate, hierarchy often provides a very powerful moral orientation for human action and desire. Indeed, in many cases it appears that people seek to re-establish the conditions for what they consider to be justice, well-being, and full human flourishing by constituting or reconstituting hierarchies rather than by seeking to abolish them. This seems to be increasingly true when people are confronted with alternative models of society and personhood. Christianity, democracy, and development, for example, often seek to challenge pre-existing social structures and values, many of which are hierarchical. It is at these conjunctures, when hierarchy is called into question, that it is often most vehemently defended and, as a result, most clearly articulated. This presents a challenge to the standard narrative of globalization. Rather than creating communities of liberal cosmopolitans, globalizing forces such as democracy and development often produce what Meyer and Geschiere (1999) have called 'cultural closure'-new longings for forms of social order that often pivot on the value of hierarchy, whether as a social form, as an ideology, or as nostalgia for an idealized past.

But cultural closure along these lines happens not only 'out there'; it also takes place in the West itself, often giving way to social movements that provoke scholars' own political reactions. In the United States, for instance, we see this sort of cultural closure among conservatives who express longing to return to the putative 'Golden Age' of the American family with its stable gender hierarchies (Ginsburg 1989). In Europe, it appears in the form of right-wing nationalist groups that seek to reassert racial hierarchies as a supposed solution to economic crisis. It may be that these more familiar, experience-near expressions 
of hierarchy are driving the renewed interest in the subject among Western scholars today. Or perhaps it is being driven by the recognition that Western society is marked by inequality to an unprecedented degree, yielding a highly stratified social order, reminiscent of feudalism, that some pundits have sought to portray as a 'natural' hierarchy (e.g., Clark 2014).

How are we to think about ideologies or social movements that reject liberal values in this manner and instead express a preference for hierarchies? Confronted with such situations where class struggle is at stake, progressives and leftists tend to resort to explanations that rely on theories of false consciousness. Even when class struggle is not a factor, it can be tempting to say that when people represent hierarchy favorably, they are merely reproducing an ideology promoted by those on the 'senior' end of the scale-men, elders, and patrons - to perpetuate the subservience of those on the 'junior' end of the scale-women, minors, and clients (e.g., Crehan 1997). These explications are not entirely without merit, but they often assume that there is something intrinsic to humans that should predispose them to reject hierarchy-an assumption that we would argue does not always bear out ethnographically. Such explanations ignore the possibility that in some contexts people might actually regard hierarchy as central to their conceptions of the good and to their ideas about human flourishing. To paraphrase the words of Saba Mahmood (2005: xi), we cannot arrogantly assume that liberal forms of life exhaust ways of living meaningfully and richly in this world. We have to be able to parochialize our own political certitude.

\section{On Wanting Hierarchy (Back): Two Examples from Southern Africa}

Southern Africa-where the two of us have conducted fieldwork for many years, and where our interest in hierarchy first emerged-provides a productive context in which to consider some of these issues. The two case studies we discuss here, from South Africa and Zambia, admittedly represent a narrow geographical and cultural focus. However, our observations can be read back on the articles in this issue that engage other regions as a means of expanding-and doubtless challenging - the framework presented in the introduction.

During the decade leading up to South Africa's first democratic elections in 1994, it became clear that not all black South Africans necessarily wanted to sign on to the vision of a liberal democratic future as promoted by the African National Congress (ANC). In rural Zululand, large numbers of people were so disturbed by the prospect that they mobilized vigilante militias under the banner of the Inkatha Freedom Party in an attempt to sabotage the ANC-led revolution. While they embraced the principles of racial equality and universal franchise, many questioned the underlying idea that all individuals are autonomous and ontologically equal-especially in relation to gender and kinship hierarchies.

This skepticism persists today. As Hickel $(2012,2015)$ has argued, many people who retain deep ties to rural areas in KwaZulu-Natal perceive liberalism as a threat to the hierarchical social order that remains crucial to their conceptions 
of fruition and collective well-being. By equalizing individuals across boundaries of gender and generation, liberalism dismantles kinship hierarchies and reduces the world to a state of sterile sameness that opens the door to serious misfortunes. Dismantle hierarchies, they say, and the very foundations of social reproduction fall apart. Many in rural KwaZulu-Natal believe that the increasing poverty and unemployment rates that characterize contemporary South Africawhich we might regard as the consequence of the government's embrace of neo-liberal economic policies-are due rather to the liberal social policies that the ANC promotes under the banner of development and progress. People who hold this view seek to restore their good fortune by ritually re-establishing or reasserting hierarchies in the home, specifically through the sacrifice of cattle and the distribution of meat.

It is tempting to regard this position-this valorization of hierarchy-as flowing from a sort of primordial location, a holdover from a premodern past. In fact, it is a wholly modern phenomenon. Hickel (2015) shows that the hierarchical order cherished by rural Zulus proceeds in part from the Native Administration policies of late colonialism, which governed rural areas by imposing a set of so-called customary laws that ossified hierarchies as a way of extending control into the minutiae of domestic life. Today, the rules of hierarchy are often naturalized as 'traditional', even though evidence suggests that social order in pre-colonial Natal was a good deal more flexible. This point serves as a cautionary tale in our present discussion. Contrary to the developmentalist trajectory presupposed by thinkers like Maine and de Tocqueville, and to some extent Dumont, hierarchy can be just as modern as individualism or egalitarianism.

Turning our attention to another ethnographic case from southern Africa, we are given a further example in which hierarchy is reasserted in the face of individualized egalitarianism. Christianity, particularly in its Protestant guises, has historically been associated with egalitarianism and individualism. Weber, Mauss, Dumont, and Foucault have been the most important thinkers behind this idea, and recent work in the anthropology of Christianity has oftenalthough not always-emphasized the individualist and egalitarian thrust of this religion (see, e.g., Robbins 2004; cf. Daswani 2011). Pentecostalism, a form of Protestantism that has witnessed exponential growth across the globe in recent decades, takes Christian egalitarianism still further through its emphasis on spiritual gifts such as prophecy and glossolalia. Because Pentecostals take seriously the biblical promise that the Holy Spirit will be poured out on "all flesh" (Joel 2: 28), regardless of age or sex, from a theological perspective theirs is among the most egalitarian forms of Christianity. Indeed, in at least some instances, Pentecostal adherence has meant the breaking down of pre-existing social hierarchies, especially those of seniority (van Dijk 1992).

Despite the egalitarian impulse of Pentecostalism, however, in many parts of the world the most important social ties developed in Pentecostal groups are structured by hierarchies of charismatic authority. This is certainly the case on the Zambian Copperbelt, where the key relationship in Pentecostal congregations is that between leaders and laypeople. As Haynes has argued in greater 
detail elsewhere (Haynes 2012, forthcoming), these ties are hierarchical and are often framed in terms of one of the most salient hierarchies in Zambiathat of generation-as on the Copperbelt pastors are regularly referred to as 'parents' (bafyashi). What this very brief ethnographic outline suggests is that in Copperbelt Pentecostalism hierarchy emerges as a clear choice in the face of other models of social organization. Yet we must also bear in mind that the Pentecostal preference for hierarchy does not mean that there is no place for egalitarian relationships. While much of Pentecostal life is devoted to creating and maintaining hierarchical ties between leaders and laypeople, the egalitarian 'charismatic space' of Pentecostal ritual (Eriksen 2014) allows existing hierarchies to be broken down or replaced when necessary, for instance, if they become corrupted by unwelcome economic interests (Haynes 2015). In this case, egalitarianism is made to serve hierarchical ends, but it has not for that reason ceased to be an important part of Pentecostal social life.

The foregoing examples, along with the various contributions to this special issue, provide a clear illustration of the sort of social movements we invoked above. Having had direct encounters with liberalism or individualism, and having been presented with spaces in which they could legitimately organize their social lives according to these principles, the groups and communities we have just described have chosen another way. In these cases, hierarchy is regarded as socially desirable, and a social world where at least some key relationships are hierarchical is considered a good to be pursued. Expressed in this way, we can begin to think of hierarchy in relation to value, and it is to this topic that we now turn.

\section{Hierarchy, Value, and Values}

Anthropological discussions of value often begin by outlining the various ways in which this term has been used in the discipline (see, e.g., Graeber 2001: 1-22; Miller 2008: 1122-1123; Otto and Willerslev 2013: 1-2). These differences are most simply described by the distinction between 'value' (use, exchange, economic) and 'values' (family, cultural, religious, aesthetic). Following David Graeber (2013: 224), who suggests that there is more commonality than difference between value and values so defined, we would like to reframe this distinction as one between 'value' as a verb and 'value' as a noun. ${ }^{6}$ The notion of value as a verb refers to the process of valuing and encompasses not only structuralist theories of value-what Graeber (2001: 2), drawing on Saussure, calls “value' ... as 'meaningful difference'”-but also economic theories of value, which are about equivalence, exchange, and so forth. In contrast, value as a noun refers to notions of the good. While this concept certainly may have moral implications, the most important feature of the good as an ethnographic object (as opposed to a philosophical one) is its connection to a certain model of sociality: values are ideas about a good social and relational world.

Understood in these terms, values as nouns can be defined as those parts of culture that transform the constellation of relationships, actions, and objects 
that we find in any society from a neutral field of open-ended potential to a field that is differentiated, a field with topography. Simply put, values value. Stated yet another way, the good structures the move from 'is' to 'ought', from difference to value, and therefore serves as the metric that animates the process of valuation-values as verbs. Without some notion of the good, it is hard to understand why someone would choose to exchange taro with a person in a neighboring village, or to build a table to sell to someone else, or to buy that same table. Nor can we see why people would prefer to marry their cross-cousins, or to regard men as more important than women, or to pursue hierarchical forms of social organization in the face of other options. These actions are rendered sensible in a framework of values that exists beyond the purely material or structural-a point that Sahlins (1976) has made very well.

Joel Robbins $(2004,2009)$ has provided a detailed description of what this process of valuation looks like in his work on the Urapmin of Papua New Guinea. For the Urapmin, a good social world is one that is characterized by the formation and maintenance of egalitarian social relationships, which are in turn fundamental to Melanesian models of the person (Strathern 1988). Following Dumont, Robbins therefore argues that the value that he calls 'relationalism' determines the position of all other elements of Urapmin society. ${ }^{7}$ This means that those ideas, institutions, or practices that most effectively produce relationships are more prominent, "more elaborately worked out" (Robbins 2009: 66), than those that do not. Here again, the particular hierarchical ordering of values as nouns-that is, the particular model of the good-found in a given community is responsible for the arrangement of all sorts of other things: the kinds of relationships people pursue, the objects they choose to display, the rituals they perform. The arrangement of values in a particular society thus reverberates through it in numerous visible ways, which means that values are observable in social life, as values "find their existence in people" (Rio and Smedal 2009b: 20).

A final thing to bear in mind when examining how values are organized is the possibility that this order can change. One can infer this not only from Dumont's (1986) work on the emergence of individualism in the West (see also Robbins 2013b), but also from Weber's (1946: 323-359) notion of value 'spheres', in which various domains of value-religious, political, aestheticcompete for superior positions of influence. In the cases provided above, we have seen how this competition can involve the position of hierarchy in the constellation of elements that make up a particular society. Similarly, it is important to pay attention to when and where hierarchy is elaborated. In most cases, hierarchy does not define all social contexts. In the examples from southern Africa discussed earlier, people might demonstrate a strong preference for hierarchy within the family or the church but reject it in other social spaces. To value hierarchy in some scenarios does not preclude an egalitarian ethic in others.

It should be clear in these southern African examples that hierarchy is central to local models of a good society. This does not mean, however, that hierarchy is a good in and of itself, but rather that hierarchy is a good because it is part of a larger ideological framework of value. In the case of rural KwaZulu-Natal, for instance, hierarchy is valued as a means to fruition-to the achievement 
of health and good fortune and the conditions for social reproduction (Hickel 2015). Indeed, in many cases people neglect kinship hierarchies until their fortunes take a turn for the worse, at which point they seek to police them with singular rigor. In the case of the Copperbelt, the importance of hierarchy follows from its connection to what Haynes (forthcoming) calls 'moving'. On the Copperbelt, moving refers to measurable advancement, whether progress through the life-course in the form of marriage and children or upward mobility indexed by consumer goods, from a new suit to a second-hand Toyota sedan. For Pentecostals, it also carries spiritual components. Importantly, moving does not refer to progress as such, but to a larger social process in which personal advancement is achieved through social relationships. Put differently, moving is not so much a matter of getting ahead as it is of being pulled up. There are multiple relational forms through which moving can be realized, but the most important of these are ties of patronage or hierarchical 'dependence' (Ferguson 2013), which facilitate moving especially well. Hierarchy is therefore important to people on the Copperbelt as a means of realizing local models of a good social world-in this case, a world in which everyone is moving.

The foregoing discussion has provided a framework through which to approach the remaining contributions to this special issue. While different articles address different aspects of the model we have developed here, and while they vary in their theoretical orientation, one nevertheless sees the thread of value running through these discussions of hierarchy.

\section{Overview of Contributions}

Signe Howell's article provides an excellent illustration of the sort of contest of values that we have already seen in the Copperbelt and Zulu cases. In the Lio example that Howell describes, the conflict between hierarchical and egalitarian social systems reveals that egalitarianism has been incorporated into Lio society without being allowed to transform it in any significant way. Traditional Lio social organization is hierarchical, and the authority of priest-leaders structures a political-religious system that Howell, using Dumont's terms, refers to as 'holist'. With the arrival of Catholicism, Lio hierarchy has been challenged by an egalitarianism that emphasizes individual relationships with God (Dumont 1986). Identification with the Catholic Church has become important to the Lio primarily as a means of interacting with the state, as national identity cards require Indonesian citizens to indicate their affiliation with one of five world religions. Lio also participate in a circumscribed set of Catholic rituals, narrowly defined according to the category of 'religion'. Nevertheless, Howell argues that hierarchy remains the encompassing value, as Catholic egalitarianism is allowed to order only less important domains of Lio life-in this case, the small, discrete category of 'religion' or occasional interactions with the state. Howell suggests that, ironically, the subordinate role given to religion, which clearly falls short of the Catholic ideal of conversion, presents a striking parallel to the way that post-Vatican II efforts toward 'inculturation' have treated culture. To wit, culture 
here is largely reduced to a set of constructed (mostly aesthetic) particles and objects, a few rituals, songs, and pieces of clothing-what Carneiro da Cunha calls "culture in quote marks" (cited in Vilaça 2014: S323). Just as Catholic practice has made culture into a reified and modular category, something to be encompassed by religion, Lio culture, as a totalizing system, has done the same with religion. For the Lio, then, a hierarchy that originated with their ancestors through the authority of priest-leaders remains the central mode of social organization, as well as, Howell adds, a model for the structure of values.

Christianity also figures in the Ethiopian Orthodox case presented by Diego Maria Malara and Tom Boylston, although to very different effect. Here, Christianity serves as part of a larger relational framework that Malara and Boylston argue structures Amhara social life. This framework is fundamentally asymmetrical and undergirds not only hierarchical patronage ties, which are familiar from the ethnographic literature on Ethiopia, but also intimate ties of love and care. Included here is the bond between a mother and child, as well as that between the Virgin Mary and Orthodox Christians. In both of these cases, love is asymmetrical because it is unconditional and can never be repaid. Love also enters into other asymmetrical ties through the work of mediators-often, again, mothers or the Virgin-who are willing and able to intercede on behalf of those they care for. It is in light of this model of 'vertical love' that Malara and Boylston are able to address the difficult question of whether we can think of hierarchy as an Amhara 'value' in the sense of a positive moral good. On the one hand, there is no question that hierarchy can lead to coercion and even exploitation. On the other, it is clear in Malara and Boylston's analysis that hierarchy is linked to some of the most intimate and important relationships in Ethiopian Orthodox society, and this is the key to understanding the place of asymmetry in Amhara relational life. As the authors put it: "Without an account of vertical love and the daily practicalities of care and affection, it is difficult to see how a system based on naked domination, as Amhara is supposed to be, could ever be livable, or how claims about the values and virtues of hierarchy could ever be convincing." In other words, if hierarchy is a value in Ethiopia, it is not because people are blind to its potentially negative effects or even simply because they enjoy the benefits of patronage. Rather, hierarchy is part of local models of the good because it is central to the politics of care, to the most important sites of intimacy and protection.

Frederick Damon's contribution takes a bold shot across time and spacedrawing on a number of classic anthropological texts and a variety of ethnographic contexts - to examine the role that destruction and sacrifice play in the production of human hierarchies. Destruction, he states, seems necessary for the creation of difference, which allows for the elaboration of rank. He begins with the example of the Kula ring, the site of his own original research. In the Kula system, when one man sends a valuable to another, he destroys part of himself: the giver's name 'goes down' (his body thereby depleted), while the receiver's name 'goes up'. In other words, exchange requires a kind of destruction, and destruction produces hierarchical difference. A similar logic operated in the past in Polynesia, Damon argues, where literal human sacrifice served as the basis for 
hierarchy, and we can also see it at play in the lynching that became so common in the United States, especially the American South during the years following the Civil War, as a method of differentiating white from black. In each of these systems, continuity needs to be replaced by tangible discontinuity or differentiation in order for some kind of hierarchized semantic field to exist. Destruction produces hierarchies, which are regarded as essential to a well-ordered social totality. Damon takes this one step further, arguing that we can understand the capitalist world system through this same lens. Why does the United States devote so much of its wealth to overdeveloping its military capacity? One might think of this as 'waste', but Damon suggests it is necessary to the continuity of the world system in two ways: it mops up overaccumulated capital in order to avoid widespread devaluation, and it maintains the relative ranking of hegemonic positions. Mass destruction-be it wasting wealth on non-productive assets such as fighter planes or laying waste to entire cities-figures as a structural component of the modern world system.

Stephan Feuchtwang's article is equally ambitious in its scope. He mounts a fresh critique of the ahistorical and structuralist dimensions of Dumont's approach to hierarchy with a corrective from another great French thinker, Dumont's teacher Marcel Mauss. While Dumont asserts a type-anti-type dualism between hierarchical and egalitarian societies, Feuchtwang derives from Mauss's theory of 'civilization'-and from Dumont's concepts of encompassment and ideology - an argument that all societies, including avowedly egalitarian ones, "hang together" on hierarchies of valuation, distinction, and aspiration. Indeed, Feuchtwang suggests that inasmuch as ideals of order, etiquette, civility, and so on are hierarchically organized and distinguished from the values of 'others' outside, hierarchy may even be intrinsic to the very concept of civilization-except in the case of specific hunter-gatherer civilizations. So much for Dumont's dualism. As a corrective to Dumont's tendency toward ahistorical analysis, Feuchtwang insists that anthropology should not shy away from exploring and analyzing the long processes by which hierarchies are formed and transformed through the history of specific civilizations. By way of example, he takes us on a dizzying tour through some 6,000 years of China's history, moving from early forms of social hierarchy in the archaeological record to the rise of the imperial dynasties, illustrating how hierarchies have changed in that context, as has the idea of civilization itself.

Arsalan Khan offers a thoughtful ethnography of the Tablighi Jamaat in Pakistan, a local instantiation of what has become the fastest growing Islamic movement in the world. Tablighis are interesting in that they maintain a strong stance against the Islamist movement that has become so powerful in Pakistan. While Islamism seeks to use state power to legislate adherence to Islamic values, Tablighis believe that such efforts are in vain. For them, the only way to draw Muslims back to Islamic piety is through proper praxis, specifically a distinct form of face-to-face preaching known as dawat, which involves extensive traveling with groups of men going house-to-house across the country. Even if these missionary efforts fail to refresh the religious commitments of others, they are important to the development of piety among the travelers themselves. Dawat is efficacious 
toward this end, not only through the discipline and sacrifice that it requires, but also through the relationships that it produces. These relationships are hierarchical, modeled on kin relations between brothers and fathers with rankings laid out along a gradient of closeness to God. As Khan puts it: "Becoming a proper Islamic subject requires that a Tablighi must learn how to live in a hierarchically structured social world as both giver and recipient of Islamic knowledge." Tablighis regard Islamist praxis, by contrast, as inefficacious because it stresses the agency and autonomy of the individual, and therefore produces persons who disregard their place in the hierarchical order. Because of this, Tablighis blame Islamism for disrupting the harmonious order of the family, causing moral chaos (fitna) in communities, and ultimately contributing to the general sense of violence and crisis that pervades Karachi today.

Finally, Olaf Smedal's discussion of hierarchy among the Ngadha of Flores, Indonesia, provides a helpful counter-example to many of the other cases treated here. Smedal describes the slow erosion of Ngadha hierarchy through the increasingly common practice of noble women marrying lower-ranking men. When this happens, a woman loses her rank and, more importantly, is not able to pass that rank along to her children. Although she can be ritually reincorporated into her family, as Smedal describes, a noble woman who has married a commoner erases aristocratic distinction in the next generation. As more and more women find themselves in this position, the long-term dissolution of Ngadha hierarchy is not difficult to imagine. Instead of defending hierarchy as socially necessary, then, the Ngadha are slowly and painfully watching it slip away. Smedal is clear that this is not a rejection of hierarchy as such-at least, not on the part of the nobility, although commoners are generally happy enough with its passing. Rather, aristocratic hierarchy seems in this example to be a victim of its own inflexibility, particularly in view of Ngadha women's increased access to education in other parts of the country, where they are unlikely to find marriage partners from the Ngadha nobility. Smedal suggests that the reason this shift is possible is that nobility was never necessary to the Ngadha social world in the first place-that while Ngadha sociality was structured by purity in a manner similar to Dumont's description of India, the social classes that exemplified purity never encompassed the whole of Ngadha society. In this way, Smedal's example provides a helpful complement to the definition of hierarchy that we have offered above by separating it from encompassment.

\section{Conclusion}

While social scientists would agree that hierarchy operates in all places, there are few who place it at the center of their analysis, and fewer still who seek to understand it on its own terms, as part of a model of a good society. In this special issue, our aim is to do precisely that-to explore people's insistence that hierarchy is good for them and for their communities, and to do so in a framework that takes these ideas seriously. What we have found is that hierarchy is remarkably assertive and that in many places it is central to local 
understandings of the good. This is not to say that hierarchy is not implicated in power relations; indeed, nearly all of the articles show that it is. However, hierarchy is much more than power and certainly much more than inequality.

As we seek to move beyond, or at least to break new ground within, the concerns that have dominated the discipline for the past two decades-namely, those of power and resistance, especially in light of the global spread of neo-liberalism-the message of this special issue is that anthropologists will do well to keep hierarchy in view. This is not to say that it is not our business to expose and denounce injustice where we find it. On the contrary, what we are suggesting is that, at least in some instances, hierarchy may in fact be a key way of resisting the atomizing effects of liberalization in particular. And even in those instances where this is not specifically the case, the critical examination of liberalism that has made such an impact on anthropology in the recent past should highlight the importance of taking seriously seemingly illiberal, hierarchical ways of organizing social life and being in the world. As our discussion in this introduction and the contributions to this special issue make clear, what emerges from a whole range of social conjunctures is the fact that people seem to want hierarchy or, in some cases, to want their hierarchy back. Anthropology must do the difficult and politically contentious work of understanding why.

\section{Acknowledgments}

This special issue got its start as a panel at the 2012 meeting of the American Anthropological Association in San Francisco. We wish to thank all of the panel participants for their support of our ideas. Thanks also to Knut Rio and the anonymous reviewers for their helpful comments. Whatever shortcomings inevitably emerge are our own.

Naomi Haynes is a Lecturer in the Department of Social Anthropology at the University of Edinburgh. Her research to date has focused on the intersection of Pentecostal Christianity with the social life and political economy of the Zambian Copperbelt. Other research interests include value, exchange, and gender. Her work has been published in the Journal of the Royal Anthropological Institute, American Anthropologist, Current Anthropology, Religion, and Ethnos. A co-curator of AnthroCyBib, an online bibliography of new work in the anthropology of Christianity, she has a forthcoming monograph entitled Moving by the Spirit.

Jason Hickel is an anthropologist at the London School of Economics. His first monograph, Democracy as Death (2015), explores how the moral values that underpin liberal democracy are contested and resisted in KwaZulu-Natal, South Africa. His work has also been published in Cultural Anthropology, History and 
Anthropology, Anthropological Quarterly, Third World Quarterly, and a number of regional journals. In addition to his academic work, he also contributes regularly to the Guardian, Al Jazeera, and other outlets. His latest book, The Divide: A New History of Global Inequality, will be published 2017.

\section{Notes}

1. What we do not offer here is a close reading and summary of Dumont's corpus, which would require another special issue in itself.

2. One of Dumont's favorite examples is that of 'goods and services'. On the one hand, services are encompassed by goods as the dominant category, included with them as essentially part of the whole. On the other, services and goods are quite different from one another and, in that difference, contrary to each other (see Dumont 1986: 252).

3. See Robbins (2013b) for an alternative reading of Dumont's apparent 'value monism'.

4. Indeed, Greg Acciaioli (2009) has argued that the definition of hierarchy as encompassment in the revised 1980 edition of Dumont's Homo Hierarchicus does not fit well with the ethnographic material presented in the same volume, which instead suggests a model of hierarchy more similar to the one we propose here.

5. In light of these examples, it may be that this definition works especially well with the material from southern Africa that we draw on in this introduction. Whether or not this is the case, we think that this definition of hierarchy is best suited to addressing those situations in which a preference for hierarchy is actively asserted, as people appear to be choosing hierarchical modes of social organization despite being confronted with other relational possibilities.

6. Although he does not use this terminology, Graeber (2001) makes a similar argument in Toward an Anthropological Theory of Value in his sustained analysis of what he calls 'action' and 'reflection' that in many ways correspond to the notion of value as a verb and as a noun, respectively. Similarly, Michael Lambek's (2013: 155) brief discussion of Marx's labor theory of value and Karl Polanyi's notion of fictitious commodities points to this distinction. Naomi Haynes also makes this point in the introduction to her forthcoming book.

7. Making good use of Dumont's ideological holism in this analysis, Robbins (2009) refers to relationalism as the 'paramount value' of the Urapmin.

\section{References}

Acciaioli, Greg. 2009. "Distinguishing Hierarchy and Precedence: Comparing Status Distinctions in South Asia and the Austronesian World, with Special Reference to South Sulawesi." Pp. 51-90 in Precedence: Social Differentiation in the Austronesia World, ed. Michael P. Vischer. Canberra: ANU E Press.

Ansell, Aaron. 2010. "Auctioning Patronage in Northeast Brazil: The Political Value of Money in a Ritual Market." American Anthropologist 112, no. 2: 283-294.

Appadurai, Arjun. 1988. "Putting Hierarchy in Its Place." Cultural Anthropology 3, no. 1: 36-49.

Barnes, John A. 1967. Politics in a Changing Society: A Political History of the Fort Jameson Ngoni. 2nd ed. Manchester: Manchester University Press. 
Bolt, Maxim. 2014. "The Sociality of the Wage: Money Rhythms, Wealth Circulation, and the Problem with Cash on the Zimbabwean-South African Border." Journal of the Royal Anthropological Institute 20, no. 1: 113-130.

Clark, Gregory. 2014. The Son Also Rises: Surnames and the History of Social Mobility. Princeton, NJ: Princeton University Press.

Crehan, Kate. 1997. The Fractured Community: Landscapes of Power and Gender in Rural Zambia. Berkeley: University of California Press.

Daswani, Girish. 2011. “(In-)Dividual Pentecostals in Ghana.” Journal of Religion in Africa 41, no. 3: 256-279.

Dumont, Louis. [1970] 1980. Homo Hierarchicus: The Caste System and Its Implications. Rev. ed. Chicago: University of Chicago Press.

Dumont, Louis. 1986. Essays on Individualism: Modern Ideology in Anthropological Perspective. Chicago: University of Chicago Press.

Eisenstadt, S. N., and Louis Roniger. 1980. "Patron-Client Relations as a Model of Structuring Social Exchange.” Comparative Studies in Society and History 22, no. 1: 42-77.

Eriksen, Annelin. 2012. "The Pastor and the Prophetess: An Analysis of Gender and Christianity in Vanuatu." Journal of the Royal Anthropological Institute 18, no. 1: $103-122$.

Eriksen, Annelin. 2014. “Sarah’s Sinfulness: Egalitarianism, Denied Difference, and Gender in Pentecostal Christianity.” Current Anthropology 55, no. S10: S262-S270.

Fabian, Johannes. 1983. Time and the Other: How Anthropology Makes Its Object. New York: Columbia University Press.

Ferguson, James. 2013. "Declarations of Dependence: Labour, Personhood, and Welfare in Southern Africa." Journal of the Royal Anthropological Institute 19, no. 2: $223-242$.

Frank, Katherine. 2006. "Agency.” Anthropological Theory 6, no. 3: 281-302.

Ginsburg, Faye D. 1989. Contested Lives: The Abortion Debate in an American Community. Berkeley: University of California Press.

Graeber, David. 2001. Toward an Anthropological Theory of Value: The False Coin of Our Own Dreams. New York: Palgrave.

Graeber, David. 2013. "It Is Value That Brings Universes into Being." HAU: Journal of Ethnographic Theory 3, no. 2: 219-243.

Haynes, Naomi. 2012. "Pentecostalism and the Morality of Money: Prosperity, Inequality, and Religious Sociality on the Zambian Copperbelt." Journal of the Royal Anthropological Institute 18, no. 1: 123-139.

Haynes, Naomi. 2015. "Egalitarianism and Hierarchy in Copperbelt Religious Practice: On the Social Work of Pentecostal Ritual.” Religion 45, no. 2: 273-292.

Haynes, Naomi. Forthcoming. Moving by the Spirit: Pentecostal Social Life on the Zambian Copperbelt. Berkeley: University of California Press.

Hickel, Jason. 2012. "Subaltern Consciousness in South Africa's Labour Movement: 'Workerism' in the KwaZulu-Natal Sugar Industry." South African Historical Journal 64, no. 3: 664-684.

Hickel, Jason. 2015. Democracy as Death: The Moral Order of Anti-Liberal Politics in South Africa. Berkeley: University of California Press.

Iteanu, André. 2013. "The Two Conceptions of Value." HAU: Journal of Ethnographic Theory 3, no. 1: 155-171.

Kapferer, Bruce 2010. “Louis Dumont and a Holist Anthropology.” Pp. 187-208 in Experiments in Holism: Theory and Practice in Contemporary Anthropology, ed. Ton Otto and Nils Bubandt. Malden, MA: Wiley-Blackwell.

Keane, Webb. 2007. Christian Moderns: Freedom and Fetish in the Mission Encounter. Berkeley: University of California Press. 
King, Diane E. 2014. Kurdistan on the Global Stage: Kinship, Land, and Community in Iraq. New Brunswick, NJ: Rutgers University Press.

Lambek, Michael. 2013. "The Value of (Performative) Acts." HAU: Journal of Ethnographic Theory 3, no. 2: 141-160.

Mahmood, Saba. 2005. Politics of Piety: The Islamic Revival and the Feminist Subject. Princeton, NJ: Princeton University Press.

Meyer, Birgit, and Peter Geschiere, eds. 1999. Globalization and Identity: Dialectics of Flow and Closure. Oxford: Blackwell.

Meyer, John W., and Ronald L. Jepperson. 2000. “The 'Actors' of Modern Society: The Cultural Construction of Social Agency." Sociological Theory 18, no. 1: 100-120.

Miller, Daniel. 2008. "The Uses of Value.” Geoforum 39, no. 3: 1122-1132.

Mosko, Mark, and Margaret Jolly, eds. 1994. Transformations of Hierarchy: Structure, History and Horizon in the Austronesian World. London: Routledge. Special issue of History and Anthropology 7, no. 1-4.

Obeyesekere, Gannanath. 1992. The Apotheosis of Captain Cook: European Mythmaking in the Pacific. Princeton, NJ: Princeton University Press.

Otto, Ton, and Rane Willerslev. 2013. "Introduction: "Value as Theory": Comparison, Cultural Critique, and Guerilla Ethnographic Theory.” HAU: Journal of Ethnographic Theory 3, no. 1: 1-20.

Peacock, Vita. 2013. "Agency and the Anstoß: Max Planck Directors as Fichtean Subjects." Anthropology in Action 20, no. 2: 6-16. Special issue on "The Study of Organisations."

Peacock, Vita. 2015. "The Negation of Hierarchy and Its Consequences." Anthropological Theory 15, no. 1: 3-21.

Pedersen, David. 2008. "Introduction: Toward a Value Theory of Anthropology." Anthropological Theory 8, no. 1: 5-8.

Pritchett, James A. 2001. The Lunda-Ndembu: Style, Change, and Social Transformation in South Central Africa. Madison: University of Wisconsin Press.

Richards, Audrey I. 1982. Chisungu: A Girl's Initiation Ceremony among the Bemba of Zambia. Pbk ed. New York: Tavistock.

Rio, Knut M., and Olaf H. Smedal, eds. 2009a. Hierarchy: Persistence and Transformation in Social Formations. New York: Berghahn Books.

Rio, Knut M., and Olaf H. Smedal. 2009b. "Hierarchy and Its Alternatives: An Introduction to Movements of Totalization and Detotalization." Pp. 1-63 in Rio and Smedal 2009a.

Robbins, Joel. 1994. "Equality as a Value: Ideology in Dumont, Melanesia, and the West." Social Analysis 36: 21-70.

Robbins, Joel. 2004. Becoming Sinners: Christianity and Moral Torment in a Papua New Guinea Society. Berkeley: University of California Press.

Robbins, Joel. 2009. "Conversion, Hierarchy, and Cultural Change: Value and Syncretism in the Globalization of Pentecostal and Charismatic Christianity." Pp. 65-88 in Rio and Smedal 2009a.

Robbins, Joel. 2013a. "Beyond the Suffering Subject: Toward an Anthropology of the Good.” Journal of the Royal Anthropological Institute 19, no. 3: 447-462.

Robbins, Joel. 2013b. "Monism, Pluralism and the Structure of Value Relations: A Dumontian Contribution to the Contemporary Study of Value." HAU: Journal of Ethnographic Theory 3, no. 1: 99-115.

Robbins, Joel. 2015. "Ritual, Value, and Example: On the Perfection of Cultural Representations." Journal of the Royal Anthropological Institute 21, no. S1: 18-29.

Sahlins, Marshall. 1976. Culture and Practical Reason. Chicago: University of Chicago Press. 
Sahlins, Marshall. 1995. How "Natives" Think: About Captain Cook, for Example. Chicago: University of Press.

Sahlins, Marshall. 2004. Apologies to Thucydides: Understanding History as Culture and Vice Versa. Chicago: University of Chicago Press.

Sahlins, Marshall. 2008. The Western Illusion of Human Nature. Chicago: Prickly Paradigm Press.

Scherz, China. 2014. Having People, Having Heart: Charity, Sustainable Development, and Problems of Dependence in Central Uganda. Chicago: University of Chicago Press.

Smith, Daniel J. 2007. A Culture of Corruption: Everyday Deception and Popular Discontent in Nigeria. Princeton, NJ: Princeton University Press.

Strathern, Marilyn. 1988. The Gender of the Gift: Problems with Women and Problems with Society in Melanesia. Berkeley: University of California Press.

Taylor, Charles. 1989. Sources of the Self: The Making of the Modern Identity. Cambridge, MA: Harvard University Press.

van Dijk, Richard A. 1992. "Young Puritan Preachers in Post-Independence Malawi." Africa 62, no. 2: 159-181.

Vilaça, Aparecida. 2014. "Culture and Self: The Different 'Gifts' Amerindians Receive from Catholics and Evangelicals." Current Anthropology 55, no. S10: S322-S332.

Weber, Max. 1946. From Max Weber: Essays in Sociology. Trans. and ed. H. H. Gerth and C. Wright Mills. New York: Oxford University Press. 